Article

\title{
Potential Application of Prunus armeniaca L. and $P$. domestica L. Leaf Essential Oils as Antioxidant and of Cholinesterases Inhibitors
}

\author{
Marco Bonesi ${ }^{1}$, Maria Concetta Tenuta ${ }^{1}$, Monica R. Loizzo ${ }^{1, *}$, Vincenzo Sicari ${ }^{2}$ and \\ Rosa Tundis ${ }^{1}$ \\ 1 Department of Pharmacy, Health Science and Nutrition, University of Calabria, Via Pietro Bucci, \\ 87036 Arcavacata di Rende (CS), Italy; marco.bonesi@unical.it (M.B.); mary.tn2006@hotmail.it (M.C.T.); \\ rosa.tundis@unical.it (R.T.) \\ 2 Department of Agricultural Science, Mediterranean University of Reggio Calabria, Via Graziella, Feo di Vito, \\ 89123 Reggio Calabria, Italy; vincenzo.sicari@unirc.it \\ * Correspondence: monica_rosa.loizzo@unical.it; Tel.: +39-098-449-3071
}

Received: 29 November 2018; Accepted: 16 December 2018; Published: 21 December 2018

check for updates

\begin{abstract}
The aim of this work is to investigate the in vitro acetylcholinesterase (AChE) and butyrycholinesterase $(\mathrm{BChE})$ inhibitory activities of essential oils obtained by hydrodistillation from the leaves of Prunus armeniaca and P. domestica in relation to their composition, analysed by Gas Chromatography-Flame Ionization Detector (GC-FID) and Gas Chromatography-Mass Spectrometry (GC-MS) analyses, at different times. Moreover, considering the role of free radicals in the progression of neurodegenerative disorders, the antioxidant properties of essential oils were investigated by using, 2'-azino-bis(3-ethylbenzothiazoline-6-sulphonic acid) (ABTS), 2,2-diphenyl-1-picrylhydrazyl (DPPH), and $\beta$-carotene bleaching tests. The relative antioxidant capacity index (RACI) was used to achieve more comprehensive comparison between analysed antioxidant effects of essential oils. P. armeniaca oils were more active than P. domestica oils against AChE. Against $\mathrm{BChE}$, the most active was the essential oil from $P$. domestica leaves collected in August with an $\mathrm{IC}_{50}$ value of $95.80 \mu \mathrm{g} / \mathrm{mL}$. This oil exerted the highest inhibitory activity of lipid peroxidation with $\mathrm{IC}_{50}$ values of 11.15 and $11.39 \mathrm{\mu g} / \mathrm{mL}$ after 30 and $60 \mathrm{~min}$ of incubation, respectively. All samples demonstrated a remarkable ABTS radicals scavenging activity, with $\mathrm{IC}_{50}$ values in the range $0.45-0.57 \mu \mathrm{g} / \mathrm{mL}$ in comparison to the positive control, ascorbic acid.
\end{abstract}

Keywords: Prunus species; leaves; essential oil; antioxidant; neuroprotection

\section{Introduction}

The prevalence of neurodegenerative disorders is increasing. Alzheimer's disease (AD) is one of the most common neurodegenerative disease characterized by cognitive impairment and gradual memory loss [1]. Anomalous deposition of amyloid plaques and neurofibrillary tangles (NFTs) in different brain regions, deficit of cholinergic neurotransmission, inflammation, and oxidative stress, are some of the pathways involved in the development and progression of $\mathrm{AD}$ [2]. Amyloid plaques are constituted by $\mathrm{A} \beta$ peptides originating from amyloid precursor protein (APP) by $\beta$ - and $\gamma$-secretase enzymes [3]. A $\beta$ peptides polymerize, forming the insoluble filaments that constitute senile plaques.

Neuro-inflammation processes, reduced cholinergic neurotransmission, microglial activation, and cytokine release also occur [4]. As stated by the cholinergic hypothesis, the reduced cholinergic neurotransmission in the cerebral cortex and the destruction of cholinergic neurons disturb cognitive function [5]. Depletion of the levels of acetylcholine has been observed in patients affected by dementia and 
in vivo studies have confirmed the role of acetylcholine in learning and memory. Thus, acetylcholinesterase (AChE) enzyme is an important target to improve the cholinergic deficit that characterizes AD [6]. Another cholinesterase, such as butyrylcholinesterase $(\mathrm{BChE}$, has been identified in humans and showed an auxiliary role in synaptic transmission. Its expression is higher in the late stage of AD.

Different in vitro and in vivo works demonstrated the occurrence of oxidative events in the course of $\mathrm{AD}$ that support the important role of oxidative stress in this pathology. In fact, it was reported that oxidative stress is linked with mitochondria dysfunction, $A \beta$-induced neuronal loss, tau protein pathology, and metal homeostasis disturbance [7]. Oxidative stress produces depletion of brain antioxidants levels, including vitamin $\mathrm{C}$, uric acid, vitamin $\mathrm{E}$, and antioxidant enzymes, including superoxide dismutase, catalase, and glutathione reductase [8]. Lipid peroxidation is enhanced in AD. The most common lipid peroxidation products found in AD patients are isoprostanoids and reactive aldehydes, such as malondialdehyde (MDA), 4-hydroxynonal, and 2-propenal. Several plant extracts and pure naturally occurring compounds, including alkaloids, polyphenols, and terpenes, have been investigated as potential new neuroprotective agents. Natural cholinesterase inhibitors, such as rivastigmine and galantamine, and $N$-methyl-D-aspartate receptor antagonists, such as memantine, are actually used for the treatment of AD. Besides anti-cholinesterases properties, most natural inhibitors of $\mathrm{AChE}$ and $\mathrm{BChE}$ have generally showed additional biological activities, principally antioxidant activity. This enables these phytochemicals to be applied as a multi-target strategy against AD. In this regard, essential oils, constituted mainly by monoterpenes hydrocarbon, sesquiterpenes hydrocarbon, oxygenated sesquiterpenes, oxygenated monoterpenes, and esters, has recently demonstrated antioxidant and neuroprotective effects $[9,10]$.

Following our previous studies in which we have investigated the potential use of different essential oils from Citrus, Salvia, Cistus, and Pinus species for the treatment of AD [11-14], herein, we analysed essential oils from the leaves of Prunus armeniaca and P. domestica collected at three different times (June, July, and August). In particular, the objectives of this study were: (i) To investigate the ability of $P$. armeniaca and $P$. domestica essential oils to inhibit $\mathrm{AChE}$ and $\mathrm{BChE}$ enzymes; (ii) to determine the antioxidant properties by using three different in vitro tests, such as 2,2'-azino-bis(3ethylbenzothiazoline-6-sulphonic acid) (ABTS), 2,2-diphenyl-1-picrylhydrazyl (DPPH), and $\beta$-carotene bleaching assays; and (iii) to evaluate the correlation of the chemical profile with the activities.

\section{Materials and Methods}

\subsection{Chemicals and Reagents}

Sodium phosphate buffer, acetylcholinesterase from Electrophorus electricus (EC 3.1.1.7, Type VI-S), butyrylcholinesterase from equine serum (EC 3.1.1.8), Tween 20, anhydrous sodium sulphate, ascorbic acid, 2,2-diphenyl-1-picrylhydrazyl (DPPH), 5,5'-dithiobis(2-nitrobenzoic-acid) (DTNB), acetylthiocholine iodide (ATCI), butyrylthiocholine iodide (BTCI), propyl gallate, $\beta$-carotene, physostigmine, and 2,2'-azino-bis(3-ethylbenzothiazoline-6-sulphonic acid) (ABTS) were acquired from Sigma-Aldrich S.p.a. (Milan, Italy). All other reagents were obtained from VWR International s.r.l. (Milan, Italy). All solvents used in this study were of analytical grade.

\subsection{Plant Materials and Essential Oils' Preparation}

Prunus armeniaca (P1-P3) and P. domestica (P4-P6) leaves were collected in Cosenza (Italy) in three months, such as June (P1, 1396 g; P4, 1892 g), July (P2, 937 g; P5, 920 g), and August (P3, 900 g; P6, 810 g) 2013, and authenticated at the Natural History Museum of Calabria and Botanic Garden, University of Calabria (Rende, Cosenza, Italy). Leaves were subjected to hydrodistillation for $3 \mathrm{~h}$, by using a Clevengertype apparatus as previously reported [14]. P. armeniaca $(1.5,1.2$, and $1.0 \mathrm{~mL}$ for P1, P2, and P3, respectively) and P. domestica (1.3, 1.5, and $2.0 \mathrm{~mL}$ for P4, P5, and P6, respectively) essential oils were stored at $+4{ }^{\circ} \mathrm{C}$ in a brown bottle under $\mathrm{N}_{2}$ until analysed for their chemical profile and tested for their bioactivity. 


\subsection{Gas Chromatography (GC-FID) and Gas Chromatography-Mass Spectrometry (GC-MS) Analyses}

P. armeniaca and P. domestica essential oils were analysed by GC-FID and GC-MS. GC-MS analyses were performed by using a Hewlett-Packard 6890 gas chromatograph (Agilent, Milan, Italy) with a HP-5 MS capillary column ( $30 \mathrm{~m}$ length, $0.25 \mathrm{~mm}$ i.d., $0.25 \mu \mathrm{m}$ film thickness) (Agilent, Milan, Italy) interfaced with a Hewlett Packard 5973 Mass Selective (EI, 70 eV) (Agilent, Milan, Italy), by using helium as the carrier gas with a flow of $1.0 \mathrm{~mL} / \mathrm{min}$. The following analytical conditions were used: $3 \mathrm{~min}$ at $50{ }^{\circ} \mathrm{C}$, then $50-280^{\circ} \mathrm{C}$ at a rate of $13^{\circ} \mathrm{C} / \mathrm{min}$; then $10 \mathrm{~min}$ at $280^{\circ} \mathrm{C}$. GC analysis was carried out on a Shimadzu GC17A (Shimadzu, Milan, Italy) equipped with a FID (Flame Ionization Detector) (Shimadzu, Milan, Italy). Essential oils were analysed on a HP-5 MS capillary column (30 m length, $0.25 \mathrm{~mm}$ i.d., $0.25 \mu \mathrm{m}$ film thickness) (Agilent, Milan, Italy), by using nitrogen as the carrier gas at a constant flow of $1.0 \mathrm{~mL} / \mathrm{min}$ and a split ratio of 1:30. Analytical conditions were: $3 \mathrm{~min}$ at $50{ }^{\circ} \mathrm{C}$, then $50-280{ }^{\circ} \mathrm{C}$ at a rate of $13{ }^{\circ} \mathrm{C} / \mathrm{min}$; then $10 \mathrm{~min}$ at $280{ }^{\circ} \mathrm{C}$. Injector and detector temperatures were maintained at 250 and $280^{\circ} \mathrm{C}$, respectively. Compounds' identification was made by comparing their mass spectral data with the Wiley 275 library and by referring to compounds available in our laboratory and/or known in the literature. Quantitative determinations were carried out by peak area normalization by using an external standard method. Data are reported in Table 1.

\subsection{In Vitro Antioxidant Activity (DPPH, ABTS, $\beta$-Carotene Bleaching Tests)}

To determine the free radicals scavenging activity of $P$. armeniaca and $P$. domestica essential oils, 2,2'-diphenypicryl hydrazyl (DPPH) and 2,2'-azino-bis(3-ethylbenzothiazoline-6-sulphonic acid) (ABTS) tests were employed testing different essential oils concentrations in the range of $62.5-100 \mu \mathrm{g} / \mathrm{mL}$ and $25-400 \mu \mathrm{g} / \mathrm{mL}$ for DPPH and ABTS test, respectively [15]. Ascorbic acid was employed as positive control.

The ability of essential oils to inhibit lipid peroxidation was explored by using the $\beta$-carotene bleaching test as previously reported [15]. Essential oils concentrations in the range of $6.25-100 \mu \mathrm{g} / \mathrm{mL}$ were tested. Measurements were carried out at initial time ( $t=0 \mathrm{~min})$, and after 30 and $60 \mathrm{~min}$ of incubation. Propyl gallate was used as a positive control.

\subsection{RACI Determination}

Relative antioxidant capacity index (RACI) was calculated. RACI is a statistical application that integrates antioxidant results obtained by using different in vitro tests and provides a reasonably accurate ranking of the antioxidant ability of investigated samples. Herein, standard scores were obtained from data from the DPPH, ABTS, and $\beta$-carotene bleaching tests without unrestricted units and no variance between the applied methods. The standard score was calculated by using the following equation: $(x-\mu) / \sigma$, where $x$ is the raw data, $\mu$ is the mean, and $\sigma$ is the standard deviation [16].

\subsection{Bioassay for Acetylcholinesterase (AChE) and Butyrylcholinesterase (BChE) Inhibitory Activity}

Acetylcholinesterase (AChE) and butyrylcholinesterase (BChE) inhibitory activity was evaluated by Ellman's method as previously described [13]. The enzyme (AChE or BChE), P. armeniaca and P. domestica essential oils, and buffer were pre-incubated for $30 \mathrm{~min}$ at $4{ }^{\circ} \mathrm{C}$. The addition of ATCI or BTCI and DTNB solution started the reaction. Then, the reaction was halted by adding physostigmine in plates placed in an ice bath. ATCI or BTCI hydrolysis was spectrophotometrically recorded at $405 \mathrm{~nm}$ and the percentage inhibition was calculated.

\subsection{Statistical Analysis}

$\mathrm{IC}_{50}$ values (concentrations giving $50 \%$ inhibition) were calculated by nonlinear regression by using Prism GraphPad Prism version 4.0 for Windows (GraphPad Software, San Diego, CA, USA). 
One-way analysis of variance test (ANOVA) followed by a multicomparison Dunnett's test were used.

Table 1. The main volatiles of P. armeniaca (P1-P3) and P. domestica (P4-P6) leaves essential oils.

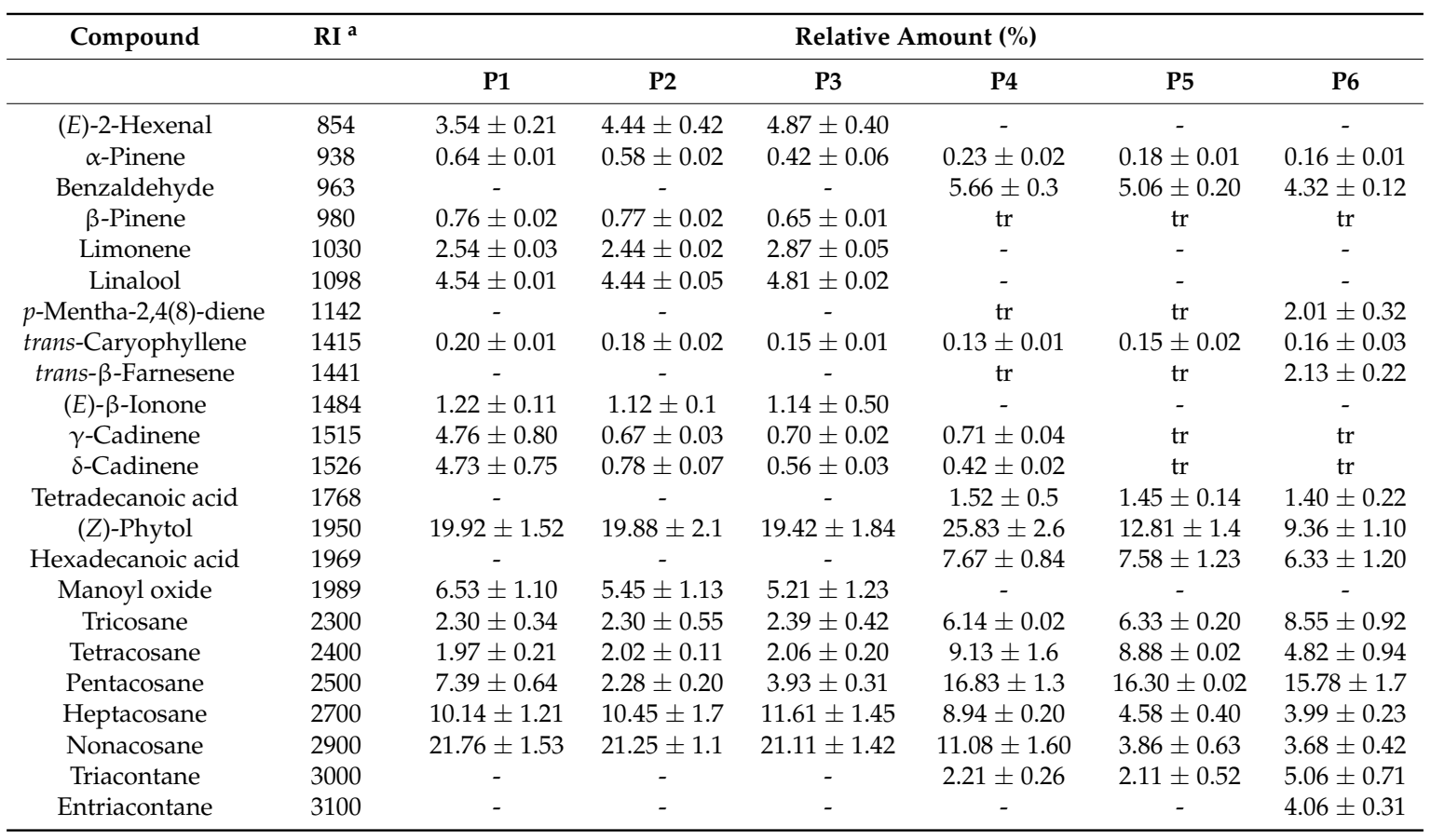

P1 and P4: essential oils from leaves collected in June; P2 and P5: essential oils from leaves collected in July; P3 and P6: essential oils from leaves collected in August. RI: Retention index. Data are reported as mean \pm standard deviation $(n=3) .{ }^{a}$ Retention indices on HP 5MS column; Compounds identification: comparison of retention times, comparison of mass spectra with mass spectrometry libraries, comparison with authentic compounds; tr: trace $(<0.1 \%)$. -: not detected.

\section{Results and Discussion}

\subsection{Chemical Composition of Essential Oils}

To identify active compounds of P. armeniaca and P. domestica essential oils, gas chromatography systems were employed. In total, 23 main volatiles were identified.

As shown in Table 1, P. armeniaca fruits were characterized mainly by phytol (19.42-19.92\%), manoyl oxide (5.21-6.53\%), linalool (4.44-4.81\%), limonene (2.44-2.87\%), and $(E)-2-h e x e n a l$ (3.54-4.87\%). The two alkanes, nonacosane (21.11-23.76\%) and heptacosane (10.14-11.61\%) were also abundant. The essential oil from P. armeniaca leaves collected in June (P1) showed high percentages of $\gamma$-cadinene $(4.76 \%), \delta$-cadinene $(4.73 \%)$, and pentacosane $(7.39 \%)$ in comparison to the other P. armeniaca oils P2 and P3.

P. domestica leaves showed pentacosane (15.78-16.83\%), phytol (25.83-9.36\%), hexadecanoic acid (6.33-7.67\%), and benzaldehyde (5.66\%) as the most abundant constituents. Other alkanes identified in high percentages were tricosane, heptacosane, and nonacosane. Some differences can be highlighted in the three months of collection (samples P4-P6). Indeed, the essential oil, P4, showed the presence of of $\gamma$-cadinene $(0.71 \%)$ and $\delta$-cadinene $(0.42 \%)$, identified in trace in the other two samples, P5 and P6. Moreover, the essential oil, P6, was characterized by the presence of $p$-mentha-2,4(8)-diene and trans- $\beta$-farnesene, and entriacontane, identified in trace in the other two oils.

The comparative analysis of essential oils from both Prunus species revealed the presence of (E)-2-hexenal, limonene, linalool, (E)- $\beta$-ionone, and manoyl oxide only in $P$. armeniaca oils. On the other hand, benzaldehyde, $p$-mentha-2,4(8)-diene, trans- $\beta$-farnesene, tetradecanoic acid, hexadecanoic acid, triacontane, and entriacontane were identified only in P. domestica essential oils. 
According to our knowledge, the literature reveals very few studies on essential oils from the leaves of P. armeniaca and P. domestica.

Only one study has reported the composition of the essential oil from P. domestica leaves [17]. Based on the results obtained in this work, $P$. domestica leaves are characterized by benzaldehyde as the dominant constituent. Instead, the volatile components of $P$. armeniaca fruits have been extensively investigated $[18,19]$.

\subsection{Bioactivities}

$\mathrm{DPPH}, \mathrm{ABTS}$, and $\beta$-carotene bleaching tests were used to investigate the antioxidant potential of $P$. armeniaca and $P$. domestica essential oils. A concentration-effects relationship was found for all essential oils (Table 2). ABTS and DPPH assays were employed to analyse the radicals scavenging activity.

A very interesting ABTS radicals scavenging activity was found for all analysed oils with Inhibitory Concentration $50 \%\left(\mathrm{IC}_{50}\right)$ values in the range $0.45-0.54 \mu \mathrm{g} / \mathrm{mL}$ in comparison to the positive control, ascorbic acid ( $\mathrm{IC}_{50}$ value of $1.70 \mu \mathrm{g} / \mathrm{mL}$ ).

In the DPPH test, the most active sample was the essential oil from P. domestica leaves collected in July (P5) with an $\mathrm{IC}_{50}$ value of $73.78 \mu \mathrm{g} / \mathrm{mL}$. The other $\mathrm{IC}_{50}$ values were in the range of $80.05-105.76 \mu \mathrm{g} / \mathrm{mL}$. The different antioxidant activity demonstrated in these tests by the essential oils may be related to the different stereochemistry and training mechanism of the ABTS and DPPH radical. For this reason, after reaction with antioxidant compounds, these radicals gave a different response [20].

$P$. domestica essential oils were more active than $P$. armeniaca essential oils in inhibiting lipid peroxidation using the $\beta$-carotene-linoleic acid test system. $\mathrm{IC}_{50}$ values in the range of $11.15-14.75 \mu \mathrm{g} / \mathrm{mL}$ and $11.39-16.19 \mu \mathrm{g} / \mathrm{mL}$ after 30 and $60 \mathrm{~min}$ of incubation were found for the essential oils, P4-P6.

Table 2. Antioxidant activity ( $\mathrm{IC}_{50}, \mu \mathrm{g} / \mathrm{mL}$ ) evaluated by 2,2-diphenyl-1-picrylhydrazyl (DPPH), 2,2'-azino-bis(3-ethylbenzothiazoline-6-sulphonic acid) (ABTS), $\beta$ carotene-bleaching test and Relative Antioxidant Capacity Index (RACI) values.

\begin{tabular}{|c|c|c|c|c|c|}
\hline Essential oil & DPPH Test & ABTS Test & \multicolumn{2}{|c|}{$\beta$-Carotene-Bleaching Test } & RACI \\
\hline \multicolumn{6}{|l|}{ P. armeniaca } \\
\hline P1 & $83.86 \pm 1.25 *$ & $0.47 \pm 0.07 *$ & $28.33 \pm 0.48 *$ & $20.73 \pm 0.54 *$ & 0.48 \\
\hline P2 & $105.76 \pm 2.81 *$ & $0.54 \pm 0.06^{*}$ & $23.05 \pm 0.65$ * & $18.55 \pm 0.57^{*}$ & 0.16 \\
\hline P3 & $80.05 \pm 2.44 *$ & $0.57 \pm 0.04$ * & $22.64 \pm 0.46^{*}$ & $17.30 \pm 0.47^{*}$ & -0.55 \\
\hline \multicolumn{6}{|l|}{ P. domestica } \\
\hline P4 & $88.33 \pm 1.90 *$ & $0.45 \pm 0.07 *$ & $14.75 \pm 0.56^{*}$ & $16.19 \pm 0.54$ * & -0.03 \\
\hline P5 & $73.78 \pm 1.64 *$ & $0.48 \pm 0.05 *$ & $14.68 \pm 0.51$ * & $13.07 \pm 0.70$ * & -1.20 \\
\hline P6 & $103.32 \pm 3.26^{*}$ & $0.50 \pm 0.04$ * & $11.15 \pm 0.43$ * & $11.39 \pm 0.53 *$ & 1.10 \\
\hline \multicolumn{6}{|l|}{ Positive control } \\
\hline Ascorbic acid & $5.01 \pm 0.83$ & $1.70 \pm 0.11$ & & & \\
\hline Propyl gallate & & & $1.0 \pm 0.04$ & $1.0 \pm 0.03$ & \\
\hline
\end{tabular}

Data are expressed as mean \pm S.D. $(n=3)$; DPPH Radical Scavenging Activity Assay; Antioxidant Capacity Determined by Radical Cation $\left(\mathrm{ABTS}^{+}\right) ; \beta$-Carotene bleaching test. Differences within and between groups were evaluated by one-way analysis of variance test followed by a multicomparison Dunnett's test. DPPH: * $p<0.01$; ABTS: ${ }^{*} p<0.01 ; \beta$-carotene-bleaching test: ${ }^{*} p<0.01$.

The statistical approach, Relative Antioxidant Capacity Index (RACI), was used to identify the sample characterized by the highest antioxidant potential. Based on this index, sample P5 showed the highest antioxidant potency (Figure 1). 


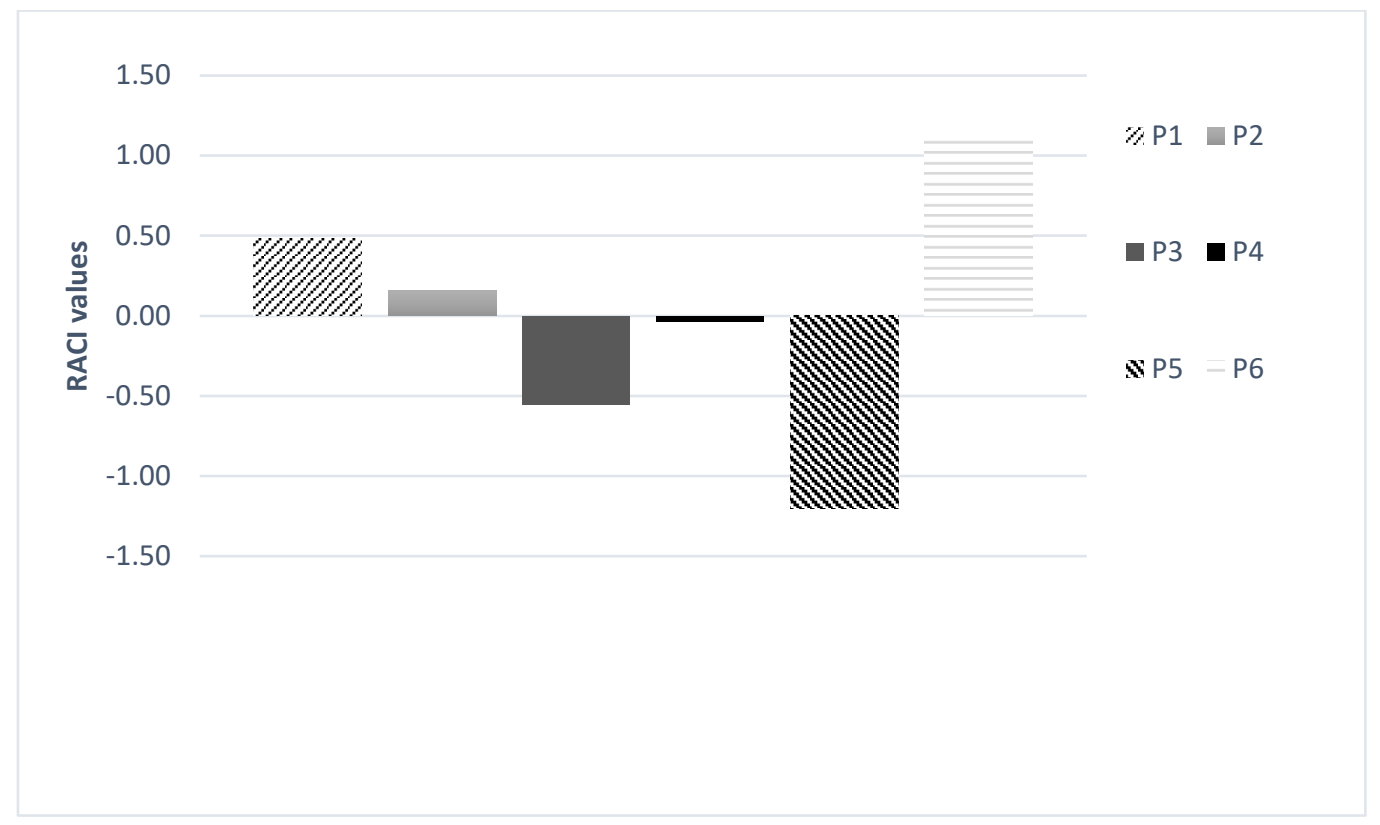

Figure 1. Relative Antioxidant Capacity Index (RACI) value of P. armeniaca (P1-P3) and P. domestica (P4-P6) essential oils.

AChE and BChE inhibitory activity were used to investigate the potential neuroprotective activity of $P$. domestica and P. armeniaca essential oils. A concentration-response relationship was observed for all tested essential oils. Table 3 reports the $\mathrm{IC}_{50}$ values.

Table 3. Acetylholinesterase (AChE) and butyrylcholinesterase (BChE) inhibitory activity of P. armeniaca and P. domestica leaves essential oils ( $\left.\mathrm{IC}_{50} \mu \mathrm{g} / \mathrm{mL}\right)$.

\begin{tabular}{ccc}
\hline Essential Oils & AChE & BChE \\
\hline P. armeniaca & & \\
\hline P1 & $97.60 \pm 1.94^{*}$ & $138.30 \pm 1.13^{*}$ \\
P2 & $98.20 \pm 1.51^{*}$ & $210.80 \pm 2.50 *$ \\
P3 & $98.50 \pm 1.96^{*}$ & $226.90 \pm 3.31^{*}$ \\
\hline P. domestica & \\
\hline P4 & $98.60 \pm 2.20^{*}$ & $209.70 \pm 1.82 *$ \\
P5 & $135.10 \pm 3.45^{*}$ & $100.20 \pm 1.42 *$ \\
P6 & $171.80 \pm 3.63^{*}$ & $95.80 \pm 1.60 *$ \\
\hline Positive control & & \\
\hline Physostigmine & $0.17 \pm 0.01$ & $2.40 \pm 0.02$ \\
\hline
\end{tabular}

Data are expressed as mean \pm S.D. $(n=3)$; AChE: Acetylcholinesterase assay; BChE: Butirrilcholinesterase assay. Differences within and between groups were evaluated by one-way analysis of variance test followed by a multicomparison Dunnett's test. AChE: ${ }^{*} p<0.01$; $\mathrm{BChE:}{ }^{*} p<0.01$.

Against AChE, the best activity was exerted by P. armeniaca essential oils, particularly by P1 with an $\mathrm{IC}_{50}$ value of $97.60 \mu \mathrm{g} / \mathrm{mL}$. This oil was characterized by the presence of phytol, $\delta$-cadinene, $\gamma$-cadinene, linalool, limonene, and $(E)$-2-hexenal as dominant constituents.

The most active in inhibiting $\mathrm{BChE}$ were P. domestica P6 and P5 oils with $\mathrm{IC}_{50}$ values of 95.80 and $100.20 \mu \mathrm{g} / \mathrm{mL}$, respectively. The other $\mathrm{IC}_{50}$ values were in the range $138.30-226.90 \mu \mathrm{g} / \mathrm{mL}$.

One of the dominant compounds that characterized the essential oil of P. armeniaca and P. domestica was phytol (3,7,11,15-tetramethylhexadec-2-en-1-ol). Phytol is a diterpene product of chlorophyll metabolism. Therefore, it is a compound abundant in nature. In a previous work [21], phytol has been demonstrated to reduce the production of free radicals. Phytol revealed a strong antioxidant activity 
due to its ability to remove hydroxyl radicals and could prevent lipid peroxidation by inhibiting the amount of Thiobarbituric Acid Reactive Species (TBARS), inhibiting cell damage caused by free radicals. Similar results were obtained with Trolox, used as a positive control. Syad et al. [22] showed an $\mathrm{IC}_{50}$ value for phytol of $95.27 \mu \mathrm{g} / \mathrm{mL}$ in the DPPH test. The same research group analysed the potential cholinesterases' inhibitory activity of this diterpene.

Phytol inhibited AChE and BChE with $\mathrm{IC}_{50}$ values of 2.70 and $5.79 \mu \mathrm{g} / \mathrm{mL}$ against $\mathrm{AChE}$ and $\mathrm{BChE}$, respectively. Different studies have demonstrated the neuroprotective activity of terpenes. Monoterpenes were mainly investigated. IC $_{50}$ values of 0.63 and $0.87 \mathrm{mM}$ were found for $\alpha$-pinene against AChE [23] and BChE [12], respectively. Previously, Miyazawa et al. [24] reported the ability of linalool to inhibit AChE with a percentage of $37 \%$ at $164 \mu \mathrm{g} / \mathrm{mL}$. Successively, Menichini et al. [25] showed $\mathrm{IC}_{50}$ values of 225.9 and $456.2 \mu \mathrm{g} / \mathrm{mL}$ for limonene against $\mathrm{AChE}$ and BChE, respectively.

\section{Conclusions}

In summary, this study reports for the first time the antioxidant and neuroprotective effects of the essential oils obtained by hydrodistillation from the leaves of P. armeniaca and P. domestica. Our results demonstrated a very interesting radical scavenging activity in the ABTS test by all investigated essential oils. P. armeniaca essential oils, particularly P1, were active in inhibiting AChE. On the other hand, P. domestica P6 and P5 were the most active in inhibiting BChE.

One of the dominant compounds that characterized essential oils of both P. armeniaca and $P$. domestica leaves was phytol, a diterpene commonly found in plants, which has previously been demonstrated to be an interesting antioxidant and neuroprotective compound. However, the unique composition of the essential oils allows for a synergistic action between individual compounds and is responsible for the found bioactivity. The obtained results underline the potential health benefits of the studied essential oils and suggest their potential use for the formulation of new products for the treatment of neurodegenerative diseases.

Author Contributions: R.T. and M.R.L. designed the experiment, V.S. prepared the manuscript, and performed statistical analyses. M.B. and M.C.T. carried out the experiments and analysed data. All authors approved the final manuscript.

Funding: This research received no external funding.

Acknowledgments: Authors thank Nicodemo Passalacqua of the Botany Department at the University of Calabria (Italy) for samples identification.

Conflicts of Interest: The authors declare no conflict of interest.

\section{References}

1. Haass, C.; Selkoe, D.J. Soluble protein oligomers in neurodegeneration: Lessons from the Alzheimer's amyloid beta-peptide. Nat. Rev. Mol. Cell Biol. 2007, 8, 101-112. [CrossRef] [PubMed]

2. Sanabria-Castro, A.; Alvarado-Echeverria, I.; Monge-Bonilla, C. Molecular pathogenesis of Alzheimer's disease: An update. Ann. Neurosci. 2017, 24, 46-54. [CrossRef] [PubMed]

3. Roher, A.E.; Kokjohn, T.A.; Clarke, S.G.; Sierks, M.R.; Maarouf, C.L.; Serrano, G.E.; Sabbagh, M.S.; Beach, T.G. $\mathrm{APP} / \mathrm{A} \beta$ structural diversity and Alzheimer's disease pathogenesis. Neurochem. Int. 2017, 12, 1-13. [CrossRef] [PubMed]

4. Barage, S.H.; Sonawane, K.D. Amyloid cascade hypothesis: Pathogenesis and therapeutic strategies in Alzheimer's disease. Neuropeptides 2015, 52,1-18. [CrossRef]

5. Fotiou, D.; Kaltsatou, A.; Tsiptsios, D.; Nakou, M. Evaluation of the cholinergic hypothesis in Alzheimer's disease with neuropsychological methods. Aging Clin. Exp. Res. 2015, 27, 727-733. [CrossRef] [PubMed]

6. Tundis, R.; Bonesi, M.; Menichini, F.; Loizzo, M.R. Recent knowledge on medicinal plants as source of cholinesterase inhibitors for the treatment of dementia. Mini Rev. Med. Chem. 2016, 16, 605-618. [CrossRef] [PubMed]

7. Zhao, Y.; Zhao, B. Oxidative stress and the pathogenesis of AD. Oxid. Med. Cell. Longev. 2013, $2013,316523$. [CrossRef] 
8. Wojtunik-Kulesza, K.A.; Oniszczuk, A.; Oniszczuk, T.; Waksmundzka-Hajnos, M. The influence of common free radicals and antioxidants on development of Alzheimer's disease. Biomed. Pharmacother. 2016, 78, $39-49$. [CrossRef]

9. Ayaz, M.; Sadiq, A.; Junaid, M.; Ullah, F.; Subhan, F.; Ahmed, J. Neuroprotective and anti-aging potentials of essential oils from aromatic and medicinal plants. Front. Aging Neurosci. 2017, 9, 168. [CrossRef]

10. Dobetsberger, C.; Buchbauer, G. Actions of essential oils on the central nervous system: An updated review. Flavour Fragr. J. 2011, 26, 300-316. [CrossRef]

11. Bonesi, M.; Menichini, F.; Tundis, R.; Loizzo, M.R.; Conforti, F.; Passalacqua, N.G.; Statti, G.; Menichini, F. Acetylcholinesterase and butyrylcholinesterase inhibitory activity of Pinus species essential oils and their constituents. J. Enz. Inhib. Med. Chem. 2010, 25, 622-628. [CrossRef] [PubMed]

12. Loizzo, M.R.; Menichini, F.; Tundis, R.; Bonesi, M.; Conforti, F.; Nadjafi, F.; Statti, G.A.; Frega, N.G.; Menichini, F. In vitro biological activity of Salvia leriifolia Benth essential oil relevant to the treatment of Alzheimer's disease. J. Oleo Sci. 2009, 58, 443-446. [CrossRef]

13. Loizzo, M.R.; Ben Jemia, M.; Senatore, F.; Bruno, M.; Menichini, F.; Tundis, R. Chemistry and functional properties in prevention of neurodegenerative disorders of five Cistus species essential oils. Food Chem. Toxicol. 2013, 59, 586-594. [CrossRef] [PubMed]

14. Tundis, R.; Loizzo, M.R.; Bonesi, M.; Menichini, F.; Mastellone, V.; Colica, C.; Menichini, F. Comparative study on the antioxidant capacity and cholinesterase inhibitory activity of Citrus aurantifolia Swingle, C. aurantium L. and C. bergamia Risso \& Poit peel essential oils. J. Food Sci. 2012, 71, H40-H46.

15. Loizzo, M.R.; Tundis, R.; Bonesi, M.; Menichini, F.; De Luca, D.; Colica, C.; Menichini, F. Evaluation of Citrus aurantifolia peel and leaves extracts for their chemical composition, antioxidant and anti-cholinesterase activities. J. Sci. Food Agric. 2012, 92, 2960-2967. [CrossRef] [PubMed]

16. Sun, T.; Tanumihardjo, S.A. An integrated approach to evaluate food antioxidant capacity. J. Food Sci. 2007, 72, R159-R165. [CrossRef] [PubMed]

17. Veličković, D.T.; Ristić, M.S.; Karabegović, I.T.; Stojičević, S.S.; Nikolić, N.Č.; Lazić, M.L. Plum (Prunus domestica) and walnut (Juglans regia): Volatiles and fatty oils. Adv. Technol. 2016, 5, 10-16.

18. Solís-Solís, H.M.; Calderón-Santoyo, M.; Schorr-Galindo, S.; Luna-Solano, G.; Ragazzo-Sánchez, J.A. Characterization of aroma potential of apricot varieties using different extraction techniques. Food Chem. 2007, 105, 829-837. [CrossRef]

19. Göğüşs, F.; Özel, M.Z.; Lewis, A.C. The effect of various drying techniques on apricot volatiles analysed using direct thermal desorption-GC-TOF/MS. Talanta 2007, 73, 321-325. [CrossRef]

20. Antolovich, M.; Prenzler, P.D.; Patsalides, E.S.; Mc Donald, S.; Robards, K. Methods for testing antioxidant activity. Analyst 2002, 127, 183-198. [CrossRef]

21. De Menezes Patrício Santos, C.C.; Stiebbe Salvadori, M.; Gomes Mota, V.; Muratori Costa, L.; Antonia Cardoso de Almeida, A.; Lopes de Oliveira, G.A.; Pereira Costa, J.; Pergentino de Sousa, D.; Mendes de Freitas, R.; Nóbrega de Almeida, R. Antinociceptive and antioxidant activities of phytol in vivo and in vitro models. Neurosci. J. 2013, 2013, 949452.

22. Syad, A.N.; Rajamohamed, B.S.; Shunmugaiah, K.P.; Kasi, P.D. Neuroprotective effect of the marine macroalga Gelidiella acerosa: Identification of active compounds through bioactivity-guided fractionation. Pharm. Biol. 2016, 54, 2073-2081. [CrossRef]

23. Perry, N.S.; Houghton, P.J.; Theobald, A.; Jenner, P.; Perry, E.K. In-vitro inhibition of human erythrocyte acetylcholinesterase by Salvia lavandulaefolia essential oil and constituent terpenes. J. Pharm. Pharmacol. 2000, 52, 895-902. [CrossRef] [PubMed]

24. Miyazawa, M.; Watanabe, H.; Umemoto, K.; Kameoka, K. Inhibition of acetylcholinesterase activity by essential oils of Mentha Species. J. Agric. Food Chem. 1998, 46, 3431-3434. [CrossRef]

25. Menichini, F.; Tundis, R.; Loizzo, M.R.; Bonesi, M.; Marrelli, M.; Statti, G.A.; Menichini, F.; Conforti, F. Acetylcholinesterase and butyrylcholinesterase inhibition of ethanolic extract and monoterpenes from Pimpinella anisoides V Brig. (Apiaceae). Fitoterapia 2009, 80, 297-300. [CrossRef] [PubMed]

(C) 2018 by the authors. Licensee MDPI, Basel, Switzerland. This article is an open access article distributed under the terms and conditions of the Creative Commons Attribution (CC BY) license (http:/ / creativecommons.org/licenses/by/4.0/). 